\title{
Teatros do real, teatros do outro: \\ a construção de territórios da alteridade a partir da presença de não-atores em espetáculos contemporâneos
}

\begin{abstract}
Julia Guimarães Mendes ${ }^{1}$
\section{Resumo}

Este artigo pretende relacionar a dimensão crítica presente nos chamados teatros do real com as estratégias de aproximação, representação e problematização do Outro que tem sido elaboradas em espetáculos contemporâneos, a partir da incorporação do discurso, testemunho e/ou da presença de não-atores. Esta análise será pautada pelo entendimento sobre quais sentidos emergem da fricção entre voz/presença de não-atores e de criadores em algumas montagens da cena atual.
\end{abstract}

Palavras-chave: Alteridade; Não-atores; Teatros do Real

\section{Abstract}

This article aims to relate the critical dimension present in the so-called theatres of the real with strategies of approximation, representation and questioning of the Other that have been developed in contemporary spectacles from the incorporation of discourse, witness and/or the presence of nonactors. The analysis will be guided by the understanding of which senses emerge from the friction between the voice/presence of non-actors and voice/presence of the creators in some performances of the current scene.

Keywords: Non-actors; Otherness; Theatres of the Real

O teatro contemporâneo, deste início de século, tem se caracterizado, dentre outros fatores, pela crescente tensão entre real e ficcional, em cena. Não é raro encontrar espetáculos no Brasil e no exterior que introduzem elementos autobiográficos, documentais e testemunhais em suas encenações, dialogando dramaturgicamente com espaços e situações reais ou trabalhando com não-atores, só para citar alguns recursos dessa estratégia representativa.

Inseridos numa perspectiva que coloca a encenação num vaivém constante entre a teatralidade e a performatividade (FÉRAL, 2011), os chamados "teatros do real" muitas vezes fazem dessa oscilação o próprio mote para a construção de sentidos

1 Doutoranda no Programa de Pós-Graduação em Artes Cênicas da Escola de Comunicação e Artes da Universidade de São Paulo - ECA/USP. Orientação: Profa. Silvia Fernandes. Bolsista da FAPESP. Mestre em Artes Cênicas pela Escola de Belas Artes da Universidade Federal de Minas Gerais - EBA/UFMG. 
em cena, seja em relação aos efeitos suscitados no espectador ou à criação dramatúrgica em si. Nesse tipo de teatro, a dosagem entre as instâncias do real e o simbólico (SÁNCHEZ, 2008), o artístico e o relacional (BOURRIAUD, 2009), a ordem da presença e da representação (FISCHER-LICHTE, 2007), a ficção e o acontecimento (PAVIS, 2010) surgem como variantes complementares e similares aos deslizamentos entre a teatralidade e a performatividade. Em conjunto, são vistos como um "novo paradigma mimético do teatro", ao promover uma "ruptura na tradicional relação dicotômica entre realidade e ficção" (BOROWSKI; SUGIERA, 2007). Para muitos autores, essa problematização das camadas representativas de um espetáculo, a partir da tentativa de anexação do real em cena, é vista como uma potente dimensão crítica do teatro contemporâneo. Numa primeira instância, a própria aproximação sobre uma dada realidade e sua problematização em cena, de forma mais direta, já aponta para uma "abertura ao mundo" que se coloca como contraponto a uma tendência, ainda em vigor, mas predominante nas décadas passadas, de o teatro apenas refletir sobre si mesmo, o que Saison chamou de crise de referência. "No contexto artístico atual, o real designa com frequência, [...] de um primeiro sobressalto, que a arte não está confinada tão somente em pensar sua própria prática"², descreve Saison (1998, p. 13).

Também para Sílvia Fernandes (2009; 2010) e Óscar Cornago (2008), haveria um deslocamento no que se refere à postura política implícita nessa aproximação com o real. No lugar do enfoque temático dos problemas sociais, procedimento comum à dramaturgia engajada dos anos 60 , o viés político vinculado aos teatros do real estaria relacionado ao desejo de "investigar as realidades sociais do outro e interrogar sobre os muitos territórios de alteridade e exclusão social do país” (FERNANDES, 2009, p. 83). Segundo Fernandes (2010), tal viés se pauta, sobretudo, pela experiência de investigação desses universos, pelo contato em si com realidades excluídas, e sua posterior anexação em cena.

Já para Cornago, esse deslocamento estaria relacionado, em última instância, à própria crise representativa que perpassa as sociedades contemporâneas. "Diante da falta de apoio, os mecanismos de representação se voltam para o exterior da cena, tentando apelar de maneira direta à realidade" (CORNAGO, 2008, p. 24). Nesse contexto, o autor aponta uma mudança de perspectiva no teatro contemporâneo, na qual as "utopias revolucionárias" se tornaram "utopias da proximidade" (CORNAGO, 
2008, p. 25). Isso porque a ideia de distância que estruturava a dimensão revolucionária no teatro parece perder sua eficácia tanto como discurso crítico quanto como estratégia de representação, uma vez que os discursos e as representações apontam para uma perspectiva banalizante, decorrente de suas múltiplas manipulações.

\section{Desse modo, a cena não chega a formular um discurso político, tampouco um mecanismo de representação. Apenas permite vislumbrar uma postura ética, uma vontade de ação frente ao outro, da qual se tenta recuperar a possibilidade do social em termos menores, não mais da ação revolucionária, com letras maiúsculas, mas sim da ação do eu em frente ao tu (CORNAGO, 2008, p. 25).}

A partir da fala de Cornago (2008, p. 26), é possível verificar um compromisso por parte dos artistas deste início de século que seria “antes ético que político”, ou seja, haveria também um deslocamento, verificado nos criadores atuais, de uma atuação crítica que estaria mais próxima de um gesto ético. Tal atitude, afirma o autor, estaria relacionada com a desintegração dos discursos sociais, com a descrença da política como representação e com a afirmação do corpo como único elemento capaz de reconstruir uma possibilidade do social, pela sua capacidade intrínseca de atuação.

Para transpor a discussão teórica apresentada aqui ao campo prático dos teatros do real, será feito um recorte em criações que, de diferentes maneiras, convocam não-atores ${ }^{3}$ a participar de seus espetáculos. Antes de partir para a análise dos estudos de caso, é interessante mapear alguns modos recorrentes de aparição desses não-atores em criações contemporâneas.

Em um primeiro patamar, que se aproxima da estrutura tradicional da ficção no teatro, esses não-atores são chamados a representar um papel. É o caso, por exemplo, do espetáculo Giulio Cesare, da companhia italiana Socìetas Raffaello Sanzio, no qual os personagens shakespearianos eram interpretados por pessoas cujo corpo chamava atenção para si, como um homem muito gordo; um senhor muito senil que mal conseguia manter-se de pé; duas meninas bulímicas e um homem que havia acabado de realizar uma traqueostomia. Como explica Fischer-Lichte (2007), havia, na montagem, a presença de um território fronteiriço, que favorecia uma oscilação na percepção do público sobre essas pessoas. Os deslizamentos ocorriam entre o que a autora chama de "ordem da presença" - relacionada à percepção do corpo singular dos intérpretes e sua fisicalidade - e "ordem da representação" - vinculada à percepção de um personagem dramático ficcional.

3 Termo criado para designar pessoas que, em oposição aos atores em seus mais diferentes graus de formação, tiveram pouco ou nenhuma vivência de aprendizagem teatral. 
Tal oscilação seria responderia não só por um processo responsável por desestabilizar a percepção do público, mas também por trazer novos significados aos próprios personagens shakespearianos. Nesse sentido, a eloquência discursiva característica do personagem Marco Antônio, por exemplo, seria paradoxalmente contrastada, na representação, com a voz de um intérprete que sofreu uma operação na laringe. Assim, o tensionamento entre realidade e ficção pela presença de não-atores que representam personagens ficcionais operaria numa lógica de constantes redimensionamentos entre uma camada e outra.

Num segundo exemplo, tem-se a vertente que busca trabalhar com as bases do teatro documentário. Nela, é possível encontrar desde criações que exploram a presença e o testemunho desses não-atores em cena tal qual nos moldes de um documentário cinematográfico, até outras que mesclam a autorreferencialidade dos não-atores com a figura de performers e/ou personagens ficcionais. Há também teatros documentários nos quais a biografia e/ou o depoimento de não-atores surgem como mote para a criação. Nesse último grupo, os não-atores podem aparecer em cena através de documentos como vídeos, gravações em áudio e/ou fotografias ou, ainda, por meio da representação dos atores, como "personagens reais".

É possível verificar ainda uma terceira maneira de inserir não-atores no teatro, relacionada a uma dimensão performativa, não-repetível e espontânea dessa participação. É o caso de espetáculos site-specific, nos quais os criadores dialogam não só com um determinado território geográfico, mas, muitas vezes, também com as pessoas que habitam aquele determinado espaço. Ao investir numa teatralização do espaço ao redor, usualmente lugares públicos, esses espetáculos também conferem algum tipo de dimensão cênica para as pessoas que ali habitam, estejam elas dialogando ou não com a criação.

Algumas vezes, essas pessoas são inseridas na dramaturgia como interlocutoras temporárias dos personagens e, neste caso, o foco recai diretamente sobre elas. No entanto, a operação de teatralizar um determinado território traz também como consequência a adoção de um processo de "clivagem" (FÉRAL, 2011, p. 146) por parte do público, que poderá, assim, enxergar sob a ótica da teatralidade algumas pessoas que estariam na região onde o espetáculo acontece. Nesse caso, a presença de não-atores em cena será fruto de uma operação subjetiva e efêmera por parte de cada espectador.

Em cada um desses exemplos, a construção de sentido operada pelas relações entre a tríade atores/não-atores/público será distinta, assim como as potencialidades 
críticas de cada uma dessas estratégias representativas. Para este estudo, interessa especificamente analisar encenações nas quais a presença de não-atores colabora para problematizar as "representações do Outro" no teatro, ou, dito de outro modo, fazer emergir complexas camadas de alteridade em um espetáculo.

Nesse contexto, um dos coletivos que mais tem privilegiado a participação de não-atores em seus trabalhos como modo de investigar questões sobre alteridade é o suíço-alemão Rimini Protokoll. Em seus espetáculos, a encenação é construída a partir da auto-representação de indivíduos de um determinado grupo social, batizados pelo coletivo como "especialista/expert de sua própria vida" (DREYSSE; MALZACHER, 2008, p. 08). Com base nas narrativas pessoais desses especialistas, os membros do coletivo elaboram um roteiro que amarra os depoimentos num determinado contexto cênico e dramatúrgico.

Embora os trabalhos possam abordar grupos muito distintos entre si-como comerciantes da Nigéria, policiais brasileiros ou políticos conservadores da Suíça - há sempre a tentativa de problematizar os discursos e seus contextos sociais, além de confrontá-los com a presença do público. Aqui, a curiosidade pelo Outro e a investigação sobre o que ele possui de mais singular costuma ser a chave da pesquisa do coletivo.

O trabalho realmente começa a partir [...] de um interesse em estranhos. Durante a produção, chega-se a um momento de cumplicidade, que é muito importante. Essa cumplicidade é possível porque você pode claramente dizer às pessoas que a razão delas estarem aqui é a sua alteridade. (HAUG apud DREYSSE; MALZACHER, 2008, p. 32)

Mais do que entender se esses especialistas estão dizendo algum tipo de verdade sobre si, interessa ao grupo identificar "como ele se apresenta, e que papel está jogando" (HAUG apud DREYSSE; MALZACHER, 2008, p. 38). Trata-se de uma aposta cujo privilégio está na representação que o Outro quer fazer de si, cuja ótica inverte a tradição do teatro de traduzir em "tipos" ou "personagens" indivíduos de um determinado grupo social.

Para pensar essa premissa, tomemos como exemplo um dos projetos do Rimini Protokoll realizados no Brasil, a performance/instalação Chácara Paraíso - Mostra de Arte Polícia (2007). Nela, pessoas que em algum momento de suas vidas atravessaram o universo policial (da atendente do 190 ao policial que atua em favelas) foram selecionadas a partir de anúncio de jornal e convocadas a participar do projeto, cuja matéria-prima seriam depoimentos biográficos pautados pela sua experiência na Polícia Militar.

Aqui, não só a multiplicidade de olhares que cada "especialista" tem sobre a controversa "instituição Polícia" contribuía para conferir diferentes ângulos sobre esse universo, como também, a partir dessa multiplicidade, construía-se um terreno fértil 
para derrubada de alguns pretensos conhecimentos e certezas sobre essa instituição por parte do público. A clássica distinção entre "bom" e "mau", frequentemente adotada ao se tratar do contexto policial, era confrontada pela exposição da subjetividade dos especialistas em diálogo com o público.

Numa perspectiva semelhante, mas através de uma estratégia de encenação distinta, outro exemplo de trabalho cênico em que a presença de um não-ator é estruturante para encenação pode ser visto no espetáculo As Rosas no Jardim de Zula, da Zula Cia. de Teatro, de Belo Horizonte. Em cena, a atriz Talita Braga recorre a uma situação biográfica e reconstrói a trajetória de sua própria mãe, Rosângela, que abandonou marido e filhos, buscando na rua um sentido para sua existência.

A base documental para a realização do espetáculo é um depoimento em vídeo de três horas que a mãe concedeu à filha. Ao contrário das experiências do Rimini Protokoll, aqui, as camadas da encenação entre o real e o ficcional surgem mais sobrepostas. O depoimento de Rosângela é encenado no plano narrativo e no plano dramático pelas duas atrizes do espetáculo, intercalado por momentos em que elas também se colocam na primeira pessoa, ao refletirem sobre a história daquela "personagem real". A figura de Rosângela também aparece em vídeo, pelo qual o público assiste alguns trechos de seu relato.

Nesse caso, o que interessa às criadoras ao trazerem uma história real como eixo dramatúrgico é questionar as representações do universo feminino e da maternidade, através de uma presença intrusa ao campo da ficção, convocada para, de algum modo, subverter lugares comuns presentes nas tradicionais abordagens sobre esses assuntos. Por meio dessa opção, é tecida uma complexa relação de alteridade no contexto de um núcleo familiar, já que a história real narrada em cena é também intimamente vinculada à história da atriz Talita Braga.

O curioso nessa relação construída no espetáculo é a própria subversão que a atriz infere sobre a biografia da mãe que a abandonou. Uma situação que poderia ser reduzida ao juízo moral do "socialmente condenável" torna-se mote para a problematização das questões do espetáculo, o que também sugere uma complexa abordagem do Outro em cena. A opção por partir de uma história real para construir o espetáculo surge como recurso capaz de gerar um potente estranhamento sobre o espectador, no intuito de desmistificar uma perspectiva engessada do que se entende por "mãe". 
Nos dois exemplos, a presença de não-atores surge como tentativa de conferir aos universos retratados certa complexidade que, algumas vezes, as representações tradicionais não conseguem alcançar, seja por apostar em fórmulas já gastas para abordar determinados temas e contextos, seja porque a própria complexidade, muitas vezes paradoxal, desses universos, parece desautorizar sua representação em um sistema fechado, como, por exemplo, na figura de um personagem dramático ou de outros modos de simbolização.

Novamente, é a própria crise da noção clássica de representação que surge nas entrelinhas dessa operação cênica. Crise esta que, segundo Sánchez (2007), estaria vinculada à dificuldade de dar forma a um mundo que "beira o irrepresentável", devido às suas múltiplas contradições e incoerências. "Devendo renunciar a uma realidade inapreensível e caótica, o teatro tentaria renovar-se mediante a introdução do real, renunciando a construir a realidade" (SÁNCHEZ, 2007, p. 140).

A fratura no processo de representação verificada nos exemplos citados acima também pode ser analisada por meio da perspectiva filosófica que Saison (1998) infere sobre os conceitos de 'Realidade', 'Real' e 'realidades.' Para a autora, o real seria visto como uma "alteridade radical", pela impossibilidade de apreendê-lo de forma direta. Segundo Saison, a única maneira de acessar esse Real seria através da busca por "realidades", tornadas, em contraponto a uma "Realidade" única, plurais e relativas. Assim, caberia aos artistas que procuram se aproximar do real "o papel de buscar atingir realidades, de testemunhar sem restituir à representação de uma Realidade" (SAISON, 1998, p. 43). Somente, então, a partir desses "olhares múltiplos, fragmentados e explodidos, que não formam jamais um sistema" (SAISON, 1998, p. 51), seria possível tangenciar o real, ou a alteridade. Ainda assim, Saison chama atenção para os perigos da "esperança ingênua de um acesso direto às coisas mesmas, sem intermediações de algum sistema representativo" (1998, p. 44).

Na medida em que nenhuma transparência é atingida, em que a multiplicação de realidades plurais desmente a ideia de uma realidade unitária que constrói o mundo, diante da falta de sentido, só nos é dado um être-là em toda a sua força, na violência factual de sua presença. (SAISON, 1998, p. 55)

Ao transpor essa operação para o projeto Chácara Paraíso, é possível dizer que o viés crítico da presença dos especialistas estaria configurado justamente pela imagem heterogênea que o mosaico de pontos de vista constrói sobre aquilo que se entende por "instituição polícia". Nesse sentido, o entendimento de real como alteridade, extraído do pensamento de Saison, permite pensar nesses "especialistas" como figuras responsá- 
veis por conferir estranheza à ficção cênica em seu sentido trivial e, consequentemente, tornam estranhas e questionáveis ao público certas verdades pré-estabelecidas.

Ao mencionar a "violência factual" da presença desse real - traduzida aqui pela participação dos não-atores - a autora também estabelece diálogo com a visão de alteridade defendida por Lévinas (SAISON, 1998). Para o filósofo, a força da presença desse Outro se configura, sobretudo, no rosto, onde estaria apresentada sua irredutível alteridade. "A significação do rosto, sua abstração, é, no sentido literal do termo, extraordinária, exterior a toda ordem" (LÉVINAS, 1993, p. 51).

Sendo assim, pode-se inferir, a partir da fala desses autores, que a construção de sentido alçada pela participação de não-atores em um projeto teatral não deve ser encarada somente pelo seu discurso, mas também pela dimensão física de sua presença, pela violenta irrupção de alteridade que emerge de seus traços e gestos, de tudo que o configura como Outro radicalmente. Muitas vezes, é a partir do estranhamento gerado pelo encontro com esses não-atores - uma presença alheia, inclusive, ao próprio código teatral - que o público pode também estranhar algumas verdades concebidas sobre si e sobre o mundo, ou, nas palavras de Saison (1998, p. 52), é o que "faz aparecer uma dimensão de alteridade em nós".

Algumas dessas premissas podem ser também exploradas para analisar a dimensão crítica subjacente ao espetáculo As Rosas no Jardim de Zula. Em comum a Chácara Paraíso, aqui também o testemunho de uma não-atriz contribui para questionar junto ao público certas verdades pré-estabelecidas, ao restituir realidades plurais em contraponto a uma Realidade unitária. No entanto, na criação da Zula Cia. de Teatro, o desejo de implodir o sistema fechado de entendimento sobre o universo materno não ocorre somente através do testemunho de não-atores.

$\mathrm{Na}$ montagem, são as próprias atrizes/criadoras que se tornam, em determinados momentos, "especialistas de si mesmas" - para usar o termo adotado pelo coletivo Rimini Protokoll -, ao colocar pontos de vista próprios e, muitas vezes, biográficos, sobre a história de Rosângela. Aqui, as constantes oscilações entre a ficcionalização de uma história real e o depoimento autobiográfico das atrizes colaboram para levar o público a desestabilizar-se também em relação às suas certezas sobre aquele universo. A existência de modos de encenação múltiplos e fragmentados favorece uma representação porosa às contradições e paradoxos que cercam aquela história, através de uma construção de sentido mais expositiva/reflexiva do que conclusiva. 
E ainda que a "personagem" Rosângela não esteja fisicamente presente no espetáculo, sua aparição em vídeo, estrategicamente inserida na cena final da montagem, consegue, mesmo sob a camada de virtualidade da tela, instaurar uma alteridade brutal na encenação. Sua presença e seu depoimento em vídeo colaboram para ressignificar a própria representação que as atrizes haviam feito dela até então, o que cria contrapontos e levanta novas camadas de reflexão em torno das questões abordadas no espetáculo.

Finalmente, vale ressaltar que tanto a criação do Rimini Protokoll quanto a da Zula Cia. de Teatro tangenciam a noção de alteridade ainda pelo viés da aproximação que realizam de territórios de exclusão social e ao ato de "dar a palavra àqueles que não tiveram acesso a ela" (SAISON, 1998, p. 21). Pois tanto a mãe que abandonou os filhos para viver no universo marginal da prostituição, quanto os profissionais que em algum momento passaram pela Polícia Militar podem ser vistos como pertencentes a grupos de algum modo depreciados ou estigmatizados pelas representações hegemônicas. Nesse âmbito, a dimensão crítica residiria justamente na inversão de status dada a quem historicamente se encontra no papel de representado e raramente no de representante, no desmascaramento de certas vozes e corpos ocultos por tais representações hegemônicas, na valorização do testemunho dessas pessoas como cerne dramatúrgico do espetáculo.

A respeito disso, Diéguez $(2011$, p. 6) afirma que o período atual estaria justamente marcado pela "crise dos representados", a quem os sistemas dominantes "têm deixado de representar." A autora enxerga nessas estratégias cênicas uma subversão capaz de "evocar ausências" e fazer "visíveis os corpos ausentes (re)presentados" (DIÉGUEZ, 2011, p. 6). Para Diéguez (2011, p. 181), esse dispositivo poderia ser entendido como "espaço de diferenças", responsável pela negação da "representação do mesmo" e pelo convite de "deslocamento até o outro".

Nesse aspecto, é possível pensar nos espetáculos também sob uma ótica filosófica, como tentativa de evitar a adequação do Outro ao Mesmo, ou aos valores de quem o representa. Nessa ótica, vale transpor para o contexto cênico a pergunta levantada por Lévinas (2009, p. 14): "Haverá ainda possibilidade para a alteridade em que o outro permanece outro na relação radicalmente?"

Vale pontuar que a motivação que leva esses artistas a incluir não-atores em seus trabalhos não parece vir de uma "tentativa heroica de ajudar o outro" (SAISON, 1998) e, 
sim, do encontro com esses universos marginais. Tal procedimento dialoga com o que Lévinas definiu como "Desejo do Outro", ou a "não-prioridade do Mesmo, [...] como se o intempestivo viesse desordenar as concordâncias da representação" (1993, p. 15).

É preciso ressaltar ainda que a participação de não-atores só terá uma concreta dimensão crítica ou potencialidade ética se houver um enquadramento, um contexto dramatúrgico e cênico que, de fato, favoreça a construção de territórios da alteridade entre eles, o público e os artistas. Até mesmo por questões de modismo, há o risco dessa estratégia se transformar em fórmula pronta e, consequentemente, reduzir a presença desses não-atores a esboços estereotipados de si mesmos.

Nesse aspecto, vale atentar para a necessidade de se compreender tais presenças não só a partir do espetáculo em si onde elas transcorrem, mas também levando em consideração os processos e a qualidade de relação construída entre os artistas e os não-atores/especialistas, além do grau de consciência dessas pessoas em relação ao papel que desempenham nas criações.

Como diria Lévinas (1993, p. 44), "a Obra pensada radicalmente é um movimento do Mesmo que vai em direção ao Outro e que jamais retorna ao Mesmo". Assim, a estratégia de fazer, no coração da linguagem cênica, emergir realidades de acordo com o ponto de vista daqueles que são compreendidos em seus contextos não só favorece uma ruptura com a tradicional indiferença em relação ao Outro que perpassa as sociedades urbanas contemporâneas como também tem o potencial de acessar a dimensão de alteridade presente em cada um, a ponto de tornar estranhas e questionáveis imagens cristalizadas que tradicionalmente construímos do mundo.

\section{Referências Bibliográficas}

BOROWSKI, Mateusz; SUGIERA, Malgorzata (org). Fictional Realities/Real Fictions: Contemporary Theatre in Search of a New Mimetic Paradigm. Newcastle: Cambridge Scholars Publishing, 2007.

BOURRIAUD, Nicolas. Estética Relacional. São Paulo: Martins Fontes, 2009.

CORNAGO, Óscar. Teatralidade e Ética. In: SAADI, Fátima; GARCIA, Silvana (org.). Próximo Ato: questões da teatralidade contemporânea. São Paulo: Itaú Cultural, 2008. p.20-31.

DEBORD, Guy. A Sociedade do Espetáculo. Rio de Janeiro: Contraponto, 1997.

DIÉGUEZ, Ileana. Cenários Liminares - teatralidades, performances e política. Uberlândia: EDUFU, 2011.

De malestares teatrales y vacíos representacionales: el teatro trascendido. Archivo Virtual de Artes Escénicas (AVAE). Disponível em: <http://artesescenicas.uclm.es>. Acesso em: 05 set. 2013.

DREYSSE, Miriam; MALZACHER, Florian (org). Experts of the Everyday. The Theatre of 
Rimini Protokoll. Berlin: Alexander Verlag, 2008.

FÉRAL, Josette. Por uma Poética da Performatividade: o teatro performativo. Sala Preta, Revista de Artes Cênicas, São Paulo, n. 8, 2008. p. 191-210.

Théorie et pratique du théâtre: au-delà des limites. Montpellier, Ed. l'Entretemps, 2011.

FERNANDES, Silvia. Teatralidades Contemporâneas. São Paulo: Perspectiva, 2010. . Teatralidades do Real. Revista Subtexto, Belo Horizonte, n.06, dez. 2009. p. 37-50.

FISCHER-LICHTE, Erika. Reality and Fiction in Contemporary Theatre. IN BOROWSKI, Mateusz; SUGIERA, Malgorzata (org). Fictional Realities/Real Fictions: Contemporary Theatre in Search of a New Mimetic Paradigm. Newcastle: Cambridge Scholars Publishing, 2007, p. 13-28.

LEHMANN, Hans-Thies. Teatro Pós-dramático. São Paulo: Cosac Naify, 2007.

LÉVINAS, Emmanuel. Humanismo do Outro Homem. Petrópolis: Vozes, 1993.

. Entre Nós: ensaios sobre a alteridade. Petrópolis: Vozes, 2009.

PAVIS, Patrice. A Encenação Contemporânea: origens, tendências, perspectivas. São Paulo: Perspectiva, 2010.

SAISON, Maryvonne, Les Théâtres du Réel. Pratiques de la Représentation dans le Théâtre Contemporain. Paris-Montreal: L'Harmattan, 1998.

SÁNCHEZ, José Antonio. Prácticas de lo Real en la Escena Contemporánea. Madrid: Visor, 2007.

\section{Sites}

Site Oficial Rimini-protokoll <http://www.rimini-protokoll.de> (acessado em 11/08/2013)

<http://www.behance.net/gallery/Chacara-Paraiso-(DEBRA)/1813157> (acessado em 11/08/2013)

$<$ http://www.chacaraparaiso.net> (acessado em 05/09/2013) 